\title{
Article
}

\section{In Vitro Growth Conditions Boost Plant Lipid Remodelling and Influence Their Composition}

\author{
Sylwia Klińska *DiD, Sara Kędzierska, Katarzyna Jasieniecka-Gazarkiewicz and Antoni Banaś \\ Intercollegiate Faculty of Biotechnology, University of Gdansk and Medical University of Gdansk, \\ 80-307 Gdansk, Poland; s.kedzierska.439@studms.ug.edu.pl (S.K.); \\ katarzyna.jasieniecka@biotech.ug.edu.pl (K.J.-G.); antoni.banas@biotech.ug.edu.pl (A.B.) \\ * Correspondence: sylwia.klinska@phdstud.ug.edu.pl
}

Citation: Klińska, S.; Kędzierska, S.; Jasieniecka-Gazarkiewicz, K.; Banaś, A. In Vitro Growth Conditions Boost Plant Lipid Remodelling and Influence Their Composition. Cells 2021, 10, 2326. https://doi.org/ $10.3390 /$ cells 10092326

Academic Editor: Sara Rinalducci

Received: 16 August 2021

Accepted: 3 September 2021

Published: 6 September 2021

Publisher's Note: MDPI stays neutral with regard to jurisdictional claims in published maps and institutional affiliations.

Copyright: (c) 2021 by the authors. Licensee MDPI, Basel, Switzerland. This article is an open access article distributed under the terms and conditions of the Creative Commons Attribution (CC BY) license (https:/ / creativecommons.org/licenses/by/ $4.0 /)$.

\begin{abstract}
Acyl-lipids are vital components for all life functions of plants. They are widely studied using often in vitro conditions to determine inter alia the impact of genetic modifications and the description of biochemical and physiological functions of enzymes responsible for acyl-lipid metabolism. What is currently lacking is knowledge of if these results also hold in real environments-in in vivo conditions. Our study focused on the comparative analysis of both in vitro and in vivo growth conditions and their impact on the acyl-lipid metabolism of Camelina sativa leaves. The results indicate that in vitro conditions significantly decreased the lipid contents and influenced their composition. In in vitro conditions, galactolipid and trienoic acid (16:3 and 18:3) contents significantly declined, indicating the impairment of the prokaryotic pathway. Discrepancies also exist in the case of acylCoA:lysophospholipid acyltransferases (LPLATs). Their activity increased about 2-7 times in in vitro conditions compared to in vivo. In vitro conditions also substantially changed LPLATs' preferences towards acyl-CoA. Additionally, the acyl editing process was three times more efficient in in vitro leaves. The provided evidence suggests that the results of acyl-lipid research from in vitro conditions may not completely reflect and be directly applicable in real growth environments.
\end{abstract}

Keywords: lipid remodelling; phosphatidylcholine; LPCAT; LPEAT; in vitro and in vivo growth conditions; acyl-lipid metabolism

\section{Introduction}

Plant cell membranes contain a double layer structure, built mainly by glycerolipids and proteins. The composition of these lipids substantially influences the fluidity and permeability of the membrane. In plants, two groups of glycerolipids can be distinguished: glycolipids and phospholipids. The former is characterised by the presence of a sugar group attached to the $s n-3$ position of the glycerol backbone, whereas in the latter the phosphate group occupies this position. Galactolipids dominate the glycerolipid pool and constitute up to $85 \%$ of all plant membrane lipids [1]. The main representatives of this group are MGDG (monogalactosyldiacylglycerol) and DGDG (digalactosyldiacylglycerol). They are present mostly in the thylakoid membrane of the chloroplast, where they form a matrix indispensable for proper photochemical reactions and the transport of electrons during photosynthesis [2-4]. The second group of compounds-phospholipids-consists mainly of phosphatidylcholine (PC), phosphatidylethanolamine (PE) and to a lesser extent phosphatidic acid (PA), phosphatidylserine (PS) and phosphatidylinositol (PI). Phospholipids occur in all plant cell membranes; however, their composition may differ between the cellular compartments. Phosphatidylcholine is the dominant phospholipid, which is also a key substrate for the production of polyunsaturated fatty acids and some uncommon fatty acids [5]. The second most abundant phospholipid is phosphatidylethanolamine. Its contents and composition strongly influence plant cell physiology by regulating the fluidity and conformation of the membranes, and by affecting the autophagy process [6-8]. The third mentioned phospholipid-phosphatidic acid—is present in limited quantities, as 
most of it is used (right after its synthesis) for membrane and storage lipid biosynthesis [5]. Moreover, PA may play an essential role in signal transduction during stress conditions, when its elevated amount is produced via phospholipase D activity [9]. Similarly, PS and PI are present in the membrane in limited amounts, and besides their role in the formation of membrane structures, they can participate in the cell signalling process $[10,11]$.

The biosynthesis of both groups of compounds is connected with diacylglycerol (DAG) pool production. DAG may be synthesised via two pathways: eucaryotic (mainly leading to phospholipid production) or procaryotic (mainly responsible for galactolipid formation). Each one is distinguished by another place of occurrence and substrate specificity of the enzymes involved [5,12]. The initial step is the same for both pathways-a reaction catalysed by glycerol-3-phosphate acyltransferase (GPAT) takes place and performs the acylation of the $s n-1$ position of the glycerol backbone. Donors of fatty acids for this reaction are acyl-ACPs (for reactions occurring in the plastid) and acyl-CoA molecules (for reactions occurring in the cytosol). The same kind of substrates are also used by the next enzymes to form these pathways-acyl-CoA:lysophosphoshatidic acid acyltransferase (LPAAT) - producing phosphatidic acid. Both enzymes exhibit different substrate specificities depending on their localisation. In the reactions catalysed by GPAT in the plastids, oleic acid is mainly attached to the $s n-1$ position, whereas in ER it is palmitic acid [11,13]. The $s n-2$ position of the formation in the plastid lysophosphatidic acid is exclusively esterified by palmitic acids and in ER mainly by oleic acid. The last step of the de novo formation of DAG is the dephosphorylation step conducted by phosphatidate phosphatase (PAP). The pool of de novo-formed DAG is further supplemented by the DAG molecules created, e.g., via phospholipase $C$ activity or the action of CDP-choline:diacylglycerol cholinephosphotransferase (CPT) or phosphatidylcholine:diacylglycerol cholinephosphotransferase (PDCT). The DAG molecules created in the cytosol can be transferred to the plastid and used for chloroplast lipid production containing unsaturated $18 \mathrm{C}$ fatty acids in the sn-2 position, while DAG formed in the plastid can be transferred to the cytosol especially in "16:3 plants" [5,14-16]. Both in plastids and in the cytosol, further formation of phospholipids or galactolipids requires the activation of one of the substrates: DAG or polar headgroup. The biosynthesis of, e.g., PE and PC requires CDP-choline or CDP-ethanolamine, respectively, and the biosynthesis of MGDG requires UDP-galactose. On the contrary, the biosynthesis of, e.g., PS and PI needs CDP-DAG [15-17].

After the de novo formation of phospholipids, they undergo constant remodelling; the deacylation process occurs and lysophospholipids are formed. In turn, these lysophospholipids are reacylated and new species of phospholipids with another set of fatty acids can be formed. Acyl-CoA:lysophospholipid acyltransferases (LPLATs) play the key role in such acyl editing of phospholipids. These enzymes are widespread among organisms and are responsible for phospholipid production from lysophospholipids (LPL) and acyl-CoA. Different groups of LPLATs can be distinguished based on their acyl acceptor preference. For instance, acyl-CoA: lysophosphatidylcholine acyltransferases (LPCATs) are characterised by the highest specificity toward lysophosphatidylcholine, acylCoA:lysophosphatidylethanolamine acyltransferase (LPEATs) toward lysophosphatidylethanolamine and previously mentioned LPAATs toward lysophospatidic acid. The deacylation process can be carried out by phospholipases, enzymes of the PDAT type (phospholipid:diacylglycerol acyltransferases) and LPLATs via backward reaction [18-22]. The relative role of the mentioned reactions in the formation of lysophospholipids is so far poorly studied; however, it may differ depending on remodelled phospholipids, plant organs and physiological stage [21,22].

From among LPLAT enzymes, LPCATs seem to play the main role in the acyl editing process. However, LPEATs and LPAATs also revealed such potential, at least in Camelina sativa seeds [21,22]. Due to the dual activity of LPLATs, they may play an essential role not only in the remodelling process of phospholipids, but also in adjusting the cytoplasmic acyl-CoA pool by suppling it with acyl-CoAs containing fatty acids derived, e.g., from remodelled PC. The effect of the environment on phospholipid remodelling and LPLAT 
activity is not well characterised. So far, only the role of LPEATs has been investigated. It was shown by Klińska et al. [23] that the activity and substrate specificity of LPEAT enzymes present in leaves are strongly regulated by temperature, which makes them a sensor of external thermal changes. Information concerning the remodelling of galactolipids is practically unavailable.

In our study, we compared two plant growth conditions: in vivo (soil pots; growth chamber) and in vitro (agar plates; liquid culture). The in vivo method imitates conditions closest to the environmental ones. As regards in vitro cultivation, this is currently the most commonly used technique for, e.g., the production of new plant varieties or secondary metabolites. In addition, this type of breeding is widely used in scientific research in the field of biology, biotechnology or agriculture in order to deepen the basic knowledge of plant physiology. It has a significant advantage over in vivo culture due to the possibility of controlling the breeding conditions, the possibility of creating the most favourable conditions for plant development or the possibility to breed without biotic stress [24]. On the other hand, the creation of artificial conditions can alter the activity of many biological processes in the cell, which may not be replicated in standard in vivo conditions. Studies comparing the types of cultures mainly concentrate on their influence on the production of secondary metabolites. Some compounds can be produced in vitro with greater intensity or the same as in vivo, or may even not be produced at all $[25,26]$. Moreover, the extracted substances derived from different plant cultivation conditions may show different properties, e.g., antioxidant or antibacterial [27].

Recently, many studies in the field of lipid biochemistry have also been conducted based on the use of in vitro cultures. Most of them concern the determination of the activity of enzymes related to lipid biosynthesis, mainly focusing on the comparison of wild lines and genetically modified ones or testing the impact of diverse abiotic stresses [28-31]. These studies often do not take into account the effect of the introduced modifications on plants grown under standard conditions (in vivo), which might be completely different, such as in the case of secondary metabolite production. The lack of knowledge about the impact of plant breeding methods on acyl-lipid metabolism, especially in vegetative tissue, drove us to conduct the first investigation into this issue. In the presented studies, we investigate the composition of acyl-lipids in leaves from plants cultivated in in vivo and in vitro growth conditions. We also determine the activity and substrate preference of different groups of acylo-CoA:lysophospholipid acyltransferases, the enzymes related to acyl-lipid biosynthesis and especially to the phospholipid remodelling process. Additionally, we evaluate the intensity of the phospholipid remodelling process occurring during in vivo and in vitro growth conditions.

\section{Materials and Methods}

\subsection{Plant Material and Growth Conditions}

Plant material was derived from Camelina sativa L. Crantz, cv. Suneson growing at two different conditions: in vivo and in vitro. For in vivo conditions, seeds of C. sativa were planted in soil and cultivated in a growth chamber at $23{ }^{\circ} \mathrm{C}$ with relative humidity at about $60 \%$ and photoperiod set for $16 \mathrm{~h}$ of light $\left(120 \mu \mathrm{mol}\right.$ photons $\left.\mathrm{m}^{-2} \mathrm{~s}^{-1}\right)$ and $8 \mathrm{~h}$ of darkness. After approximately 35 days from sowing, before plants started to bloom, leaves were harvested for further analysis. In case of leaf material derived from in vitro conditions, firstly $C$. sativa seeds were planted on plates containing: $2 \%$ sucrose, $0.8 \%$ agar and $0.5 \times$ Murashige and Skoog (MS) medium, preceded by surface sterilisation of seeds. Subsequently, after 10 days, well-developed seedlings were transferred into the liquid culture containing $0.5 \times$ MS medium supplemented with $2 \%$ sucrose for the next 14 days. In vitro cultivation was conducted in long-day photoperiod at $23^{\circ} \mathrm{C}$ with shaking $(100 \mathrm{rpm})$.

\subsection{Lipid Analysis}

Lipid extraction from in vivo and in vitro leaves or from microsomal fractions prepared from these leaves was conducted according to the modified method described by Bligh and 
Dyer [32]. The tissues/microsomes were homogenised in $3.75 \mathrm{~mL}$ of chloroform:methanol $(1: 2, v / v)$ followed by the addition of $1.25 \mathrm{~mL}$ of $0.15 \mathrm{M}$ acetic acid, $1.25 \mathrm{~mL}$ of chloroform and $1.25 \mathrm{~mL}$ of water. The chloroform fractions, containing lipids, were collected and separated by TLC on Silica gel 60 plates (Merck, Darmstadt, Germany) with chloroform:methanol:acetic acid:water (90:15:10:2.5, $v / v / v / v)$ as solvent system. The plates with separated lipid classes were sprayed with $0.05 \%$ primuline solution and visualised under UV light. Based on used lipid standard, areas of gel containing appropriate lipid classes were scraped off and methylated in situ on the gel with $2 \% \mathrm{H}_{2} \mathrm{SO}_{4}$ in dry methanol (45 min at $90{ }^{\circ} \mathrm{C}$ ). The fatty acid methyl esters were extracted by addition of $3 \mathrm{~mL}$ of hexane and $2 \mathrm{~mL}$ of water. The internal standard — methyl heptadecanoate (17:0-Me) — was added right after methylation. Analysis of contents and composition of fatty acid methyl esters of the prepared samples was conducted by gas-liquid chromatography (Shimadzu; GC-2010) equipped with a fame ionisation detector (FID) and a $60 \mathrm{~m} \times 0.25 \mathrm{~mm} \mathrm{CP-WAX} \mathrm{58-CB}$ fused-silica column (Agilent Technologies, Santa Clara, CA, USA).

\subsection{Microsomal Membrane Preparation}

Isolation of membrane fraction from in vivo and in vitro leaves was performed according to the method previously described by Klinska et al. [21]. In summary, the collected leaf material was thoroughly ground in glass homogenisers with extraction buffer $(0.1 \mathrm{M}$ potassium phosphate buffer- $\mathrm{pH} 7.2,1 \mathrm{mg} / \mathrm{mL}$ of BSA, $0.33 \mathrm{M}$ sucrose and catalase $(1000 \mathrm{U} / \mathrm{mL}))$. Obtained homogenates were filtered through Miracloth and centrifuged at $20,000 \times g$ for 12 min to get rid of non-ground tissues and undesirable cell compartments. Supernatants were centrifuged for the second time at $100,000 \times g$ for $90 \mathrm{~min}$ and the resulting pellets - containing microsomal fraction-were resuspended in $0.1 \mathrm{M}$ potassium phosphate buffer ( $\mathrm{pH}$ 7.2). Aliquots of microsomal fraction were collected for measurement of their "concentration" via determination of phosphatidylcholine contents by method described above. Microsomal fractions were stored at $-80^{\circ} \mathrm{C}$ for further analysis.

\subsection{Enzyme Assay}

Enzyme assay determining the activity and the substrate specificity of the three acylCoA:lysophospholipid acyltransferases-LPAAT, LPCAT and LPEAT-was conducted on microsomal fractions derived from in vivo and in vitro C. sativa leaves. For enzymatic reactions, previously established parameters for these enzymes present in seeds and leaves were used [21,23]. As acyl donors, ten various acyl-CoAs were used: decanoyl-CoA $\left(\left[{ }^{14} \mathrm{C}\right] 10: 0-\mathrm{CoA}\right)$, lauroyl-CoA $\left(\left[{ }^{14} \mathrm{C}\right] 12: 0-\mathrm{CoA}\right)$, myristoyl-CoA $\left(\left[{ }^{14} \mathrm{C}\right] 14: 0-\mathrm{CoA}\right)$, palmitoylCoA $\left(\left[{ }^{14} \mathrm{C}\right] 16: 0-\mathrm{CoA}\right)$, stearoyl-CoA $\left(\left[{ }^{14} \mathrm{C}\right] 18: 0-\mathrm{CoA}\right)$, oleoyl-CoA $\left(\left[{ }^{14} \mathrm{C}\right] 18: 1-\mathrm{CoA}\right)$, linoleoylCoA ( $\left.\left[{ }^{14} \mathrm{C}\right] 18: 2-\mathrm{CoA}\right)$, linolenoyl-CoA $\left(\left[{ }^{14} \mathrm{C}\right] 18: 3-\mathrm{CoA}\right)$, eicosenoyl-CoA $\left(\left[{ }^{14} \mathrm{C}\right] 20: 1-\mathrm{CoA}\right)$ and erucoyl-CoA $\left(\left[{ }^{14} \mathrm{C}\right] 22: 1-\mathrm{CoA}\right)$. Mentioned $\left[1-{ }^{14} \mathrm{C}\right]$ acyl-CoAs were synthesised according to the modified method described by Sánchez et al. [33] by using appropriate [1- $\left.{ }^{14} \mathrm{C}\right] \mathrm{fatty}$ acids (purchased from Larodan AB, Sweden or American Radiolabeled Chemicals, MO, USA) and coenzyme A (Sigma-Aldrich, MO, USA).

For determination of the activity of LPCAT, LPEAT and LPAAT type of enzymes in the prepared microsomal fractions, to the reaction mixtures we added, respectively: 5 nmol of

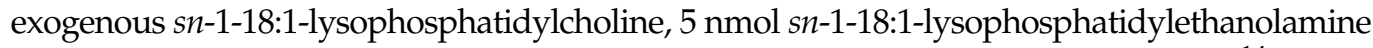
or $5 \mathrm{nmol}$ of $s n-1-18: 1$-lysophoshatidic acid together with $5 \mathrm{nmol}$ of appropriate [ $\left.{ }^{14} \mathrm{C}\right]$ acylCoA and aliquots of microsomal fractions (equivalent to $0.2 \mathrm{nmol}$ and $0.5 \mathrm{nmol}$ of the endogenous PC). Reaction mixtures were filled up to $100 \mu \mathrm{L}$ with $40 \mathrm{mM}$ potassium buffer ( $\mathrm{pH} 7.2$ ). Reactions were carried out at $30^{\circ} \mathrm{C}$ for $30 \mathrm{~min}$ (for LPCAT) and for $60 \mathrm{~min}$ (for LPAAT and LPEAT) with continuous shaking (1250 rpm). Enzymatic reactions were terminated by addition of $375 \mu \mathrm{L}$ of chloroform:methanol $(1: 2 ; v: v), 5 \mu \mathrm{L}$ of glacial acetic acid and $125 \mu \mathrm{L}$ of chloroform. Following mixing and centrifugation, chloroform fractions were collected and separated by thin-layer chromatography on silica gel 60 plates (Merck, Darmstadt, Germany) using polar solvent system (chloroform:methanol:acetic acid:water; 90:15:10:2,5; v:v:v:v). The reaction products, $\left[{ }^{14} \mathrm{C}\right]-\mathrm{PC},\left[{ }^{14} \mathrm{C}\right]-\mathrm{PE}$ or of $\left[{ }^{14} \mathrm{C}\right]-\mathrm{PA}$ 
were visualised and quantified using electronic autoradiography (Instant Imager, Packard Instrument Co., Meriden, CT, USA).

For measurement of the intensity of remodelling of PC, PE and PA and the effect of different acyl-CoAs on this process, to the reaction mixture aliquots of microsomal fractions containing $10 \mathrm{nmol}$ of endogenous PC together with $10 \mathrm{nmol}$ of oleoyl-CoA $\left(\left[{ }^{14} \mathrm{C}\right] 18: 1-\right.$ CoA), linoleoyl-CoA $\left(\left[{ }^{14} \mathrm{C}\right] 18: 2-\mathrm{CoA}\right)$ or linolenoyl-CoA $\left(\left[{ }^{14} \mathrm{C}\right] 18: 3-\mathrm{CoA}\right)$ and $1 \mathrm{mg}$ of BSA were added. The reaction mixtures were filled up to $100 \mu \mathrm{L}$ with $40 \mathrm{mM}$ potassium buffer ( $\mathrm{pH}$ 7.2) and incubated at $30{ }^{\circ} \mathrm{C}$ with continuous shaking (1250 rpm) for 5 and $60 \mathrm{~min}$ (modified method described by Klińska et al. [23]). Reactions were stopped as described above for LPLAT activity assays. The reaction products $\left(\left[{ }^{14} \mathrm{C}\right] \mathrm{PC},\left[{ }^{14} \mathrm{C}\right] \mathrm{PE}\right.$ and $\left.\left[{ }^{14} \mathrm{C}\right] \mathrm{PA}\right)$ were analysed as described above.

\section{Results}

\subsection{Contents and Composition of Fatty Acids of Acyl-Lipids in Analysed Leaves}

To estimate the acyl-lipid contents in the analysed tissues, the aliquots of chloroform extracts were evaporated to dryness and underwent a methylation procedure (see Materials and Methods). The obtained fatty acid methyl esters were then analysed on GC. The peaks of separated fatty acids were identified by comparison of their retention times with the retention time of fatty acid standards. The concentration of a given fatty acid in the analysed samples was obtained by comparison of the size of its peak with the size of the peak of the internal standard (17:0-Me). Both calculations were performed automatically by software connected to GC.

The obtained results showed that the total acyl-lipid contents in the analysed in vivo and in vitro leaves of $C$. sativa differed significantly. In vivo leaves contained over 2.5 times more acyl-lipids per unit of dry weight than their counterparts from in vitro cultures (Figure 1). The dominating fatty acid in acyl-lipids of in vivo leaves was linolenic acid (18:3) followed by hexadecatrienoic acid (16:3), palmitic acid (16:0), linoleic acid (18:2) and oleic acid (18:1). Their relative amounts accounted for around: $55 \%, 17 \%, 13 \%, 8 \%$ and $3 \%$, respectively. The other identified fatty acids (18:0, 20:3, 20:4 and 24:1) did not exceed 1\% (individually) of the total fatty acid contents. In acyl-lipids of in vitro leaves, 18:3 accounted for about $48 \%$ of the total fatty acids, $18: 2$ for about $18 \%, 16: 0$ for $17 \%, 18: 1$ for $6 \%, 16: 3$ for $4 \%$ and $18: 0$ for about $3 \%$. The other detected fatty acids (20:3, 20:4 and 24:1) constituted a very minor part of the total fatty acids, similarly to in vivo leaves (Figure 2). Thus, the fatty acid composition of acyl-lipids of in vitro leaves differed substantially from that of in vivo leaves. Especially 16:3 contents were lower-4\% versus $17 \%$. Additionally, the relative amount of $18: 3$ went down by about $7 \%$. On the contrary, the relative amount of $18: 2$ increased by about $10 \%, 16: 0$ by about $4 \%$ and $18: 1$ and $18: 0$ by about $3 \%$ each. To conclude, in vitro conditions lowered the unsaturation of acyl-lipids in comparison to in vivo conditions.

\subsection{Lipid Classes in Analysed Leaves of C. sativa from In Vivo and In Vitro Conditions}

To examine lipid classes present in the tested leaves, the chloroform extracts were separated by TLC and further analysed on GC. The fatty acid contents in each lipid class were then summed up and, next, the fatty acid contents in each lipid classes were divided by this sum and multiplied by 100 . The results were treated as a relative percentage of a given lipid class in the total acyl-lipids present in the analysed tissues. 

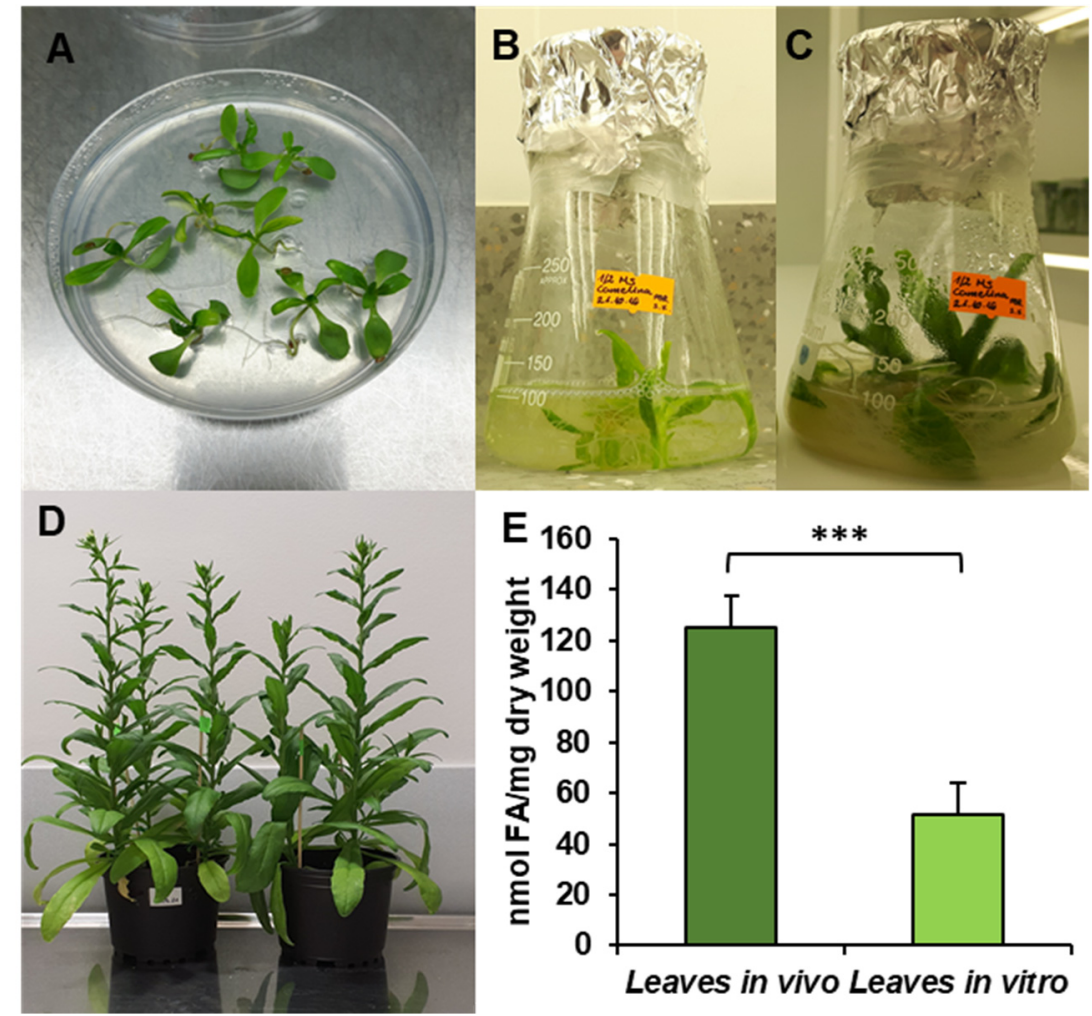

Figure 1. Cultivation conditions-in vitro (A-C), in vivo (D) and fatty acid contents in C. sativa tested leaves (E). (A) Ten-day-old seedling before transfer to liquid culture; (B) 17-day-old seedling, week after transfer to liquid conditions; (C) 24-day-old seedling used for microsomal preparation and lipid analysis; (D) in vivo plants used for the experiments; (E) contents of fatty acids in leaves cultivated in vivo and in vitro. Mean values and SD are presented (data from at least three independent assays). Asterisks indicate significant difference between fatty acid contents in leaves cultivated in vivo and in vitro in a two-tailed Student's $t$-test: ${ }^{* *} p \leq 0.001$.

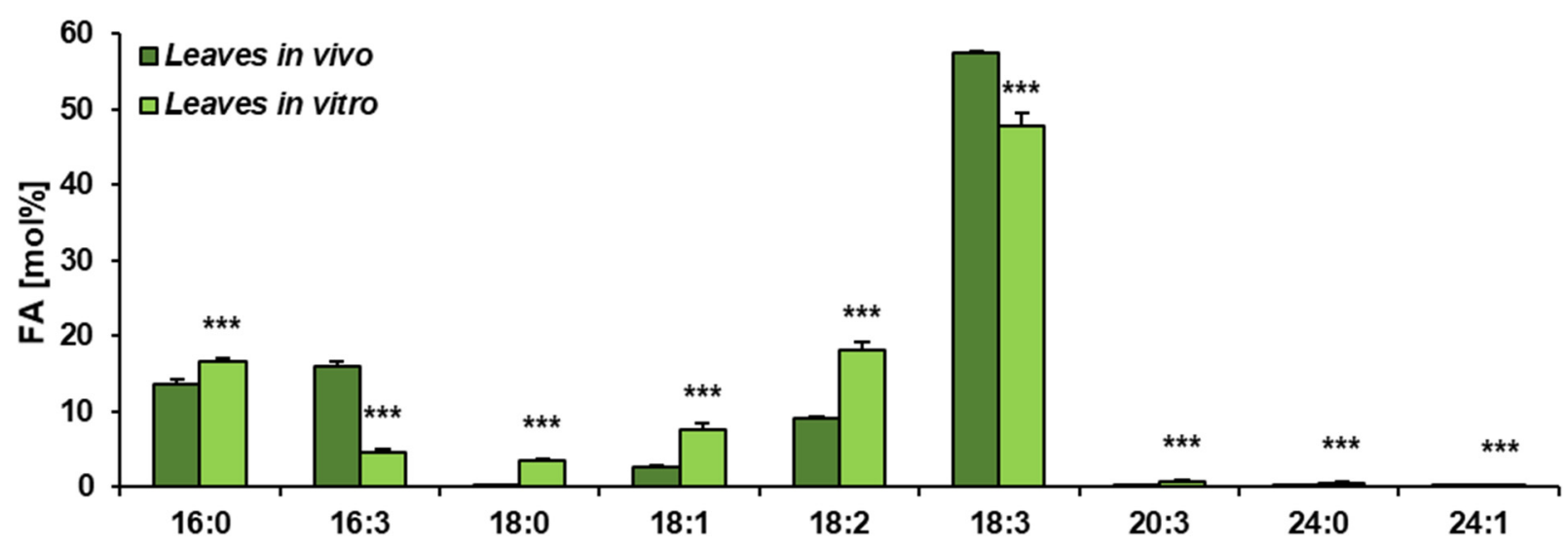

Figure 2. Fatty acid composition of acyl-lipids present in C. sativa leaves cultured in in vivo and in vitro conditions. Mean values and SD are presented (data from at least three independent assays). Asterisks indicate significant difference between relative amounts of each fatty acid of acyl-lipids in leaves cultivated in vivo and in vitro in a two-tailed Student's $t$-test: *** $p \leq 0.001$.

The obtained results showed that the growth conditions significantly affected the composition of lipid classes present in leaves of $C$. sativa. In vivo leaves contained about $45 \%$ of MGDG, about $20 \%$ of PC and DGDG (each one), close to $9 \%$ of PE, around $3 \%$ of neutral lipids (analysed as one class) and small amounts of PI, PS, SQDG, PG and PA- 
oscillating around $1 \%$ for each of them. The dominating lipid class in leaves from in vitro conditions was PC, accounting for about $41 \%$ of all lipids. MGDG accounted for about $23 \%$ and neutral lipids for $18 \%$. PE constituted about $12 \%$ of all acyl-lipids and DGDG about $3 \%$. PI, PS, SQGD, PG and PA were present in very small amounts, similarly to leaves from in vivo conditions. Thus, in vitro conditions significantly diminished the galactolipid contents-from about $65 \%$ to about $26 \%$ of all acyl-lipids. A significant increase was noted in the case of PC (from $20 \%$ in vivo to about $41 \%$ in in vitro conditions) and neutral lipids (analysed as one class) - by about 15\%. PE contents increased by about 3\% (Figure 3).

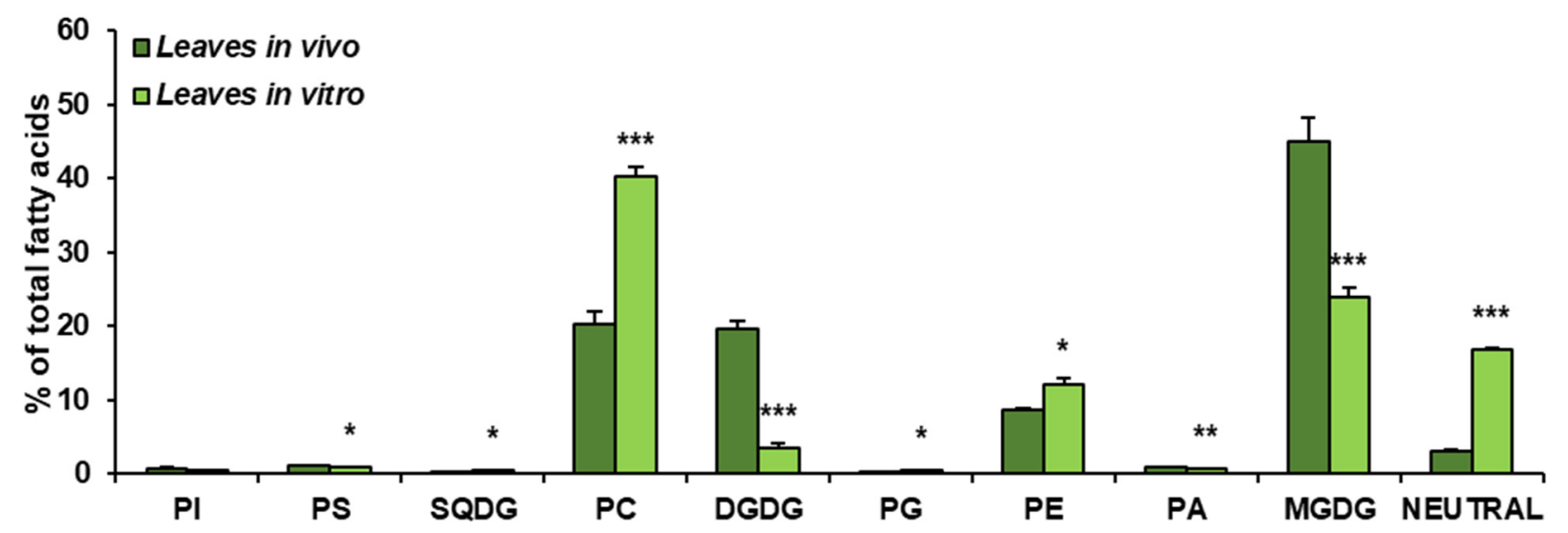

Figure 3. Lipid classes present in C. sativa leaves cultured in in vivo and in vitro conditions. Mean values and SD are presented (data from at least three independent assays). Asterisks indicate significant difference between relative amounts of each lipid class of leaves cultivated in vivo and in vitro in a two-tailed Student's $t$-test: ${ }^{*} p \leq 0.05,{ }^{* *} p \leq 0.01,{ }^{* * *} p \leq 0.001$.

\subsection{Fatty Acid Composition of Main Lipid Classes of C. sativa Leaves from In Vivo and In Vitro Conditions}

Detailed analyses of fatty acid compositions were performed for the two main phospholipids (PE and PC) and for the two main glycolipids (MGDG and DGDG). All analysed lipids contained significant amounts of the following fatty acids: 16:0, 18:0, 18:1, 18:2 and 18:3, and small amounts of 20:3, 24:0 and 24:1 (presented in the table as a sum with the name "others"). Galactolipids additionally comprised 16:3 (Table 1). The relative amount of detected fatty acids depended on the analysed lipid and growth conditions.

PE from in vitro conditions contained, e.g., 16:0, 18:2 and 18:3 in almost equal amounts (25-28\%). Additionally, it contained about $10 \%$ of $18: 1,5 \%$ of "others" and $4 \%$ of $18: 0$. PE of leaves from in vivo condition contained similar amounts of 18:0, 18:2 and 18:3; however, the relative amount of 16:0 increased to about $37 \%$ and $18: 1$ and "others" decreased to 6 and $1.5 \%$, respectively.

The main fatty acid of PC of C. sativa leaves was 18:3. However, in PC of leaves from in vivo conditions it constituted about $68 \%$ of all fatty acids, and in PC of leaves from in vitro conditions it constituted only about $46 \%$. On the other hand, in vitro conditions strongly increased $18: 1$ and $18: 2$ contents (from 0.9 to $9.7 \%$ and from 4.3 to $17.7 \%$, respectively). The relative amounts of 16:0,18:0 and "others" were similar in both growth conditions.

MGDG of $C$. sativa leaves from both growth conditions contained predominantly trienoic fatty acids (18:3 and 16:3). However, the in vitro conditions decreased their amount substantially. The relative contents of $16: 3$ went down from $30 \%$ to about $19 \%$ and $18: 3$ from about 63 to about $59 \%$. In contrast, in vitro conditions elevated the relative amount of 16:0 (from 4 to $6 \%$ ), $18: 1$ (from 0.5 to $3.6 \%$ ) and $18: 2$ (from 3 to $11 \%$ ). 
Table 1. Distribution of different fatty acids in major/chosen phospholipids and galactolipids present in C. sativa leaves cultured in in vivo and in vitro conditions. In "others" pool, 20:1, 20:2, 20:3, 22:0, 24:0 and 24:1 are present. Mean values and $\mathrm{SD}$ are presented (data from at least three independent assays). Asterisks indicate significant difference between relative amounts of fatty acids present in each analysed lipid class in leaves cultivated in vivo and in vitro in a two-tailed Student's t-test: ${ }^{*} p \leq 0.05,{ }^{* *} p \leq 0.01,{ }^{* * *} p \leq 0.001$.

\begin{tabular}{|c|c|c|c|c|c|c|c|c|}
\hline \multirow[t]{2}{*}{$\begin{array}{l}\text { Lipid } \\
\text { Class }\end{array}$} & \multirow{2}{*}{$\begin{array}{c}\text { Type of } \\
\text { Cultivation } \\
\text { Condition }\end{array}$} & \multicolumn{7}{|c|}{ Fatty Acids (mol\%) } \\
\hline & & $16: 0$ & $16: 3$ & 18:0 & $18: 1$ & $18: 2$ & $18: 3$ & Others \\
\hline \multirow{2}{*}{ PE } & In vitro & $\begin{array}{l}25.5 \\
\pm 0.2\end{array}$ & - & $\begin{array}{c}4.0 \\
\pm 0.01\end{array}$ & $\begin{array}{c}10.6^{* * *} \\
\pm 0.1\end{array}$ & $\begin{array}{l}26.4 \\
\pm 0.2\end{array}$ & $\begin{array}{l}28.4 \\
\pm 0.8\end{array}$ & $\begin{array}{l}5.0 \text { ** } \\
\pm 0.2\end{array}$ \\
\hline & In vivo & $\begin{array}{l}37.4 \\
\pm 3.0 \\
\end{array}$ & - & $\begin{array}{c}4.8 \\
\pm 0.4 \\
\end{array}$ & $\begin{array}{c}5.9 \\
\pm 0.3 \\
\end{array}$ & $\begin{array}{l}24.0 \\
\pm 1.8 \\
\end{array}$ & $\begin{array}{l}26.3 \\
\pm 1.7 \\
\end{array}$ & $\begin{array}{c}1.5 \\
\pm 0.01 \\
\end{array}$ \\
\hline \multirow{2}{*}{ PC } & In vitro & $\begin{array}{l}20.8 \\
\pm 0.3\end{array}$ & - & $\begin{array}{c}4.2 \\
\pm 0.01\end{array}$ & $\begin{array}{c}9.7^{* * *} \\
\pm 0.1\end{array}$ & $\begin{array}{c}17.7^{* * *} \\
\pm 0.1\end{array}$ & $\begin{array}{c}46.5^{* * *} \\
\pm 0.2\end{array}$ & $\begin{array}{c}1.2 \\
\pm 0.1\end{array}$ \\
\hline & In vivo & $\begin{array}{l}21.9 \\
\pm 2.5\end{array}$ & - & $\begin{array}{c}3.2 \\
\pm 1.01\end{array}$ & $\begin{array}{c}0.9 \\
\pm 0.1\end{array}$ & $\begin{array}{c}4.3 \\
\pm 0.2\end{array}$ & $\begin{array}{l}68.0 \\
\pm 3.0\end{array}$ & $\begin{array}{c}1.4 \\
\pm 0.2\end{array}$ \\
\hline \multirow{2}{*}{ MGDG } & In vitro & $\begin{array}{l}6.2^{* *} \\
\pm 0.1\end{array}$ & $\begin{array}{c}19.4^{* *} \\
\pm 0.3\end{array}$ & - & $\begin{array}{c}3.6^{* * *} \\
\pm 0.1\end{array}$ & $\begin{array}{c}11.4^{* * *} \\
\pm 1.3\end{array}$ & $\begin{array}{c}58.8^{* *} \\
\pm 0.9\end{array}$ & $\begin{array}{c}0.6 \\
\pm 0.01 \\
\end{array}$ \\
\hline & In vivo & $\begin{array}{c}4.0 \\
\pm 0.2 \\
\end{array}$ & $\begin{array}{l}30.0 \\
\pm 1.4 \\
\end{array}$ & - & $\begin{array}{c}0.5 \\
\pm 0.4 \\
\end{array}$ & $\begin{array}{c}3.0 \\
\pm 0.4 \\
\end{array}$ & $\begin{array}{l}62.6 \\
\pm 0.6 \\
\end{array}$ & - \\
\hline \multirow{2}{*}{ DGDG } & In vitro & $\begin{array}{l}37.4 \\
\pm 1.3\end{array}$ & $\begin{array}{l}4.8 \\
\pm 0.1\end{array}$ & - & $\begin{array}{l}8.6^{*} \\
\pm 0.6\end{array}$ & $\begin{array}{l}23.4 \text { * } \\
\pm 0.6\end{array}$ & $\begin{array}{c}25.4^{* *} \\
\pm 0.1\end{array}$ & $\begin{array}{c}0.5 \\
\pm 0.01\end{array}$ \\
\hline & In vivo & $\begin{array}{l}33.4 \\
\pm 1.0\end{array}$ & $\begin{array}{c}5.7 \\
\pm 0.3\end{array}$ & - & $\begin{array}{c}12.2 \\
\pm 1.0\end{array}$ & $\begin{array}{c}17.9 \\
\pm 0.8\end{array}$ & $\begin{array}{l}30.8 \\
\pm 0.8\end{array}$ & - \\
\hline
\end{tabular}

The fatty acid composition of DGDG of $C$. sativa leaves was also affected by the growth conditions. The relative amount of 18:1 accounted for about $12 \%$ in in vivo conditions and for about $9 \%$ in in vitro conditions. The contents of $18: 3$ also decreased from $30 \%$ to about $25 \%$ and $16: 3$ from $5.7 \%$ to $4.8 \%$. The in vitro conditions increased, on the other hand, the relative amount of 16:0 (by about $4 \%$ ) and 18:2 (by about $5.5 \%$ ).

3.4. Activity and Substrate Specificity of Acyl-CoA:lysophospholipid Acyltransferases of C. sativa Leaves from In Vivo and In Vitro Conditions

Microsomal fractions prepared from leaves of C. sativa from in vivo and in vitro conditions were used in assays evaluating the activity and specificity of acyl-CoA:lysophospholipid acyltransferases. Three types of assays were performed, specific for LPCATs, LPEATs and LPAATs. The results of assays with appropriate lysophospholipids together with 16:0-CoA or 18:2-CoA were selected for the presentation of the activity of the mentioned types of acyltransferases in the analysed microsomal fractions. The activity is shown as pmol of de novo synthesised $\left[{ }^{14} \mathrm{C}\right]$ phospholipid during $1 \mathrm{~min}$ by aliquots of microsomal fractions containing $1 \mathrm{nmol}$ of microsomal PC (approximately $0.44 \mu \mathrm{g}$ of microsomal proteins). As a product of LPCAT, LPEAT and LPAAT actions, $\left[{ }^{14} \mathrm{C}\right] \mathrm{PC},\left[{ }^{14} \mathrm{C}\right] \mathrm{PE}$ and $\left[{ }^{14} \mathrm{C}\right] \mathrm{PA}$, respectively, were considered. All of the assayed LPLAT activity was significantly higher in microsomal fractions of leaves from in vitro conditions. For LPCAT activity it was 2.8 and 2.5 times higher, for LPEAT activity 3.8 and 7 times higher and for LPAAT activity 2 and 2.5 times higher in assays with 16:0-CoA and 18:2-CoA, respectively. Both in assays with microsomal fractions from in vivo and in vitro conditions, LPCATs and LPEATs utilised 18:2-CoA about 2 to 3.5 times better than 16:0-CoA. On the contrary, LPAATs utilised 16:0-CoA about 1.2 times better than 18:2-CoA (Figure 4). 

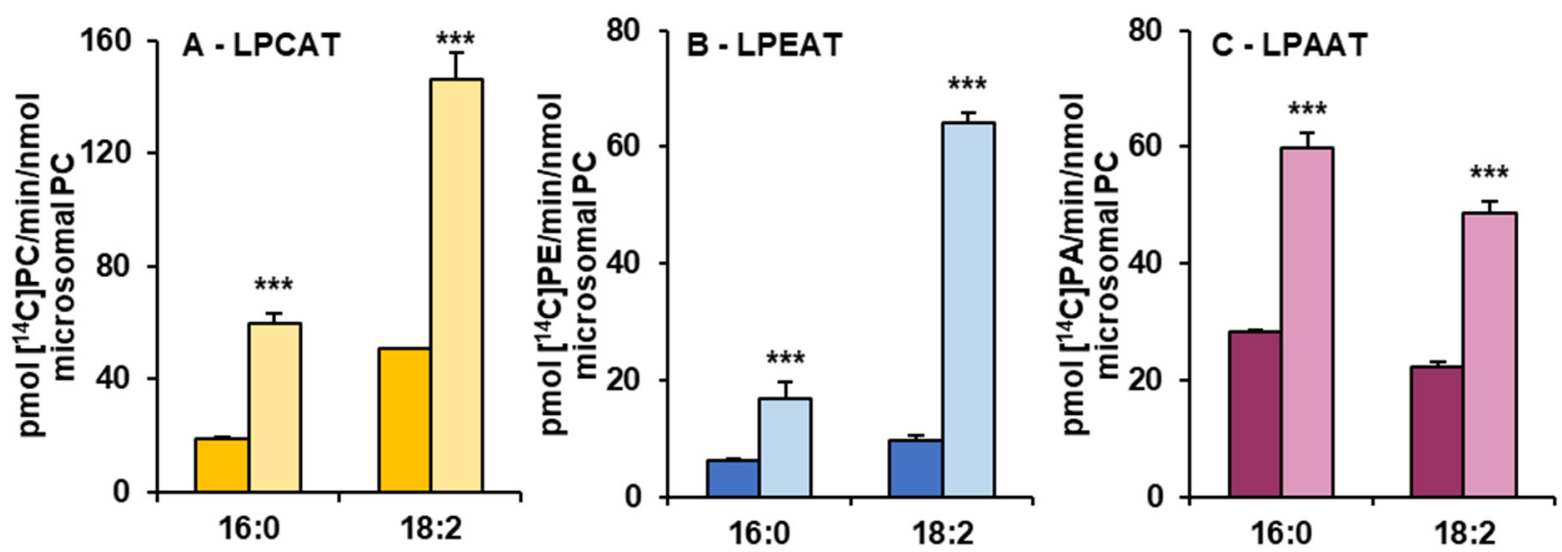

Figure 4. The activity of LPCAT (A), LPEAT (B) and LPAAT (C) enzymes of microsomal fractions of $C$. sativa leaves from two different growth conditions: in vivo and in vitro. Assays contained appropriate sn-1-LPL as fatty acid acceptor and 16:0-CoA or 18:2-CoA (indicated on the figure as 16:0 and 18:0, respectively) as fatty acid donors. Mean values and SD are presented (data from at least three independent assays). Asterisks indicate significant difference between the activity of the tested LPLATs (in assays with tested acyl donors) present in leaves cultivated in vivo (left bar) and in vitro (right bar) in a two-tailed Student's $t$-test: ${ }^{* * *} p \leq 0.001$.

For the detailed substrate specificity analyses of the tested LPLATs towards acyl-CoAs, assays containing combinations of appropriate lysophospholipids (LPC, LPE and LPA, respectively, for assaying LPCAT, LPEAT and LPAAT specificity) with 10 different acylCoAs were conducted. To facilitate the comparison of the affinity of the tested enzymes towards the tested acyl-CoAs, the obtained activities are shown as the percentage of activity towards 16:0-CoA (reference activity).

The LPCATs present in microsomal fractions from both in vivo and in vitro C. sativa leaves showed the highest activity towards acyl-CoA with $18 \mathrm{C}$ unsaturated fatty acids. The activity was $2-3$ times higher than towards $16: 0-\mathrm{CoA}$. Growth conditions only slightly modified their specificity. LPCATs from in vitro conditions utilised 18:3-CoA the most efficiently and from in vivo conditions 18:2-CoA. The relative affinity towards the other tested acyl-CoAs was much smaller than towards 16:0-CoA and was similar in assays with both types of microsomal fractions (Figure 5).

However, the in vitro conditions significantly increased the relative activity of LPEATs towards 18:1-CoA (from equal to activity towards 16:0-CoA to about two times higher), 18:2-CoA (from about $150 \%$ to about $370 \%$ ) and towards $18: 3-\mathrm{CoA}$ (from $80 \%$ to about $150 \%$ of activity towards 16:0-CoA). The relative activity of LPEATs towards 10:0-CoA, 12:0-CoA, 14:0-CoA, 20:1-CoA and 22:1-CoA oscillated between 5 and $20 \%$ of the reference activity and was a bit lower in assays with in vitro microsomal fractions. Additionally, activity towards 18:0-CoA went down from about $37 \%$ to about $27 \%$ of the reference one (Figure 5).

The relative activity of LPAATs from in vitro conditions increased for most of the tested acyl-CoAs compared to LPAATs from in vivo conditions. The most striking was the increase in preferences towards 18:1-CoA (from equal to the activity towards 16:0-CoA to 1.8 times higher). The activity towards 10:0-CoA increased from $6 \%$ to $20 \%$ of the reference activity, towards $12: 0-\mathrm{CoA}$ from $18 \%$ to $48 \%$, towards $18: 0-\mathrm{CoA}$ from $12 \%$ to $23 \%$ and towards 20:1-CoA from 3\% to $6 \%$. The activity towards $18: 3-\mathrm{CoA}$ increased from about $53 \%$ to $79 \%$ of the reference activity and towards $14: 0-\mathrm{CoA}$ and 18:2-CoA remained similar, like in assays with microsomal fractions from in vivo conditions (Figure 5). 


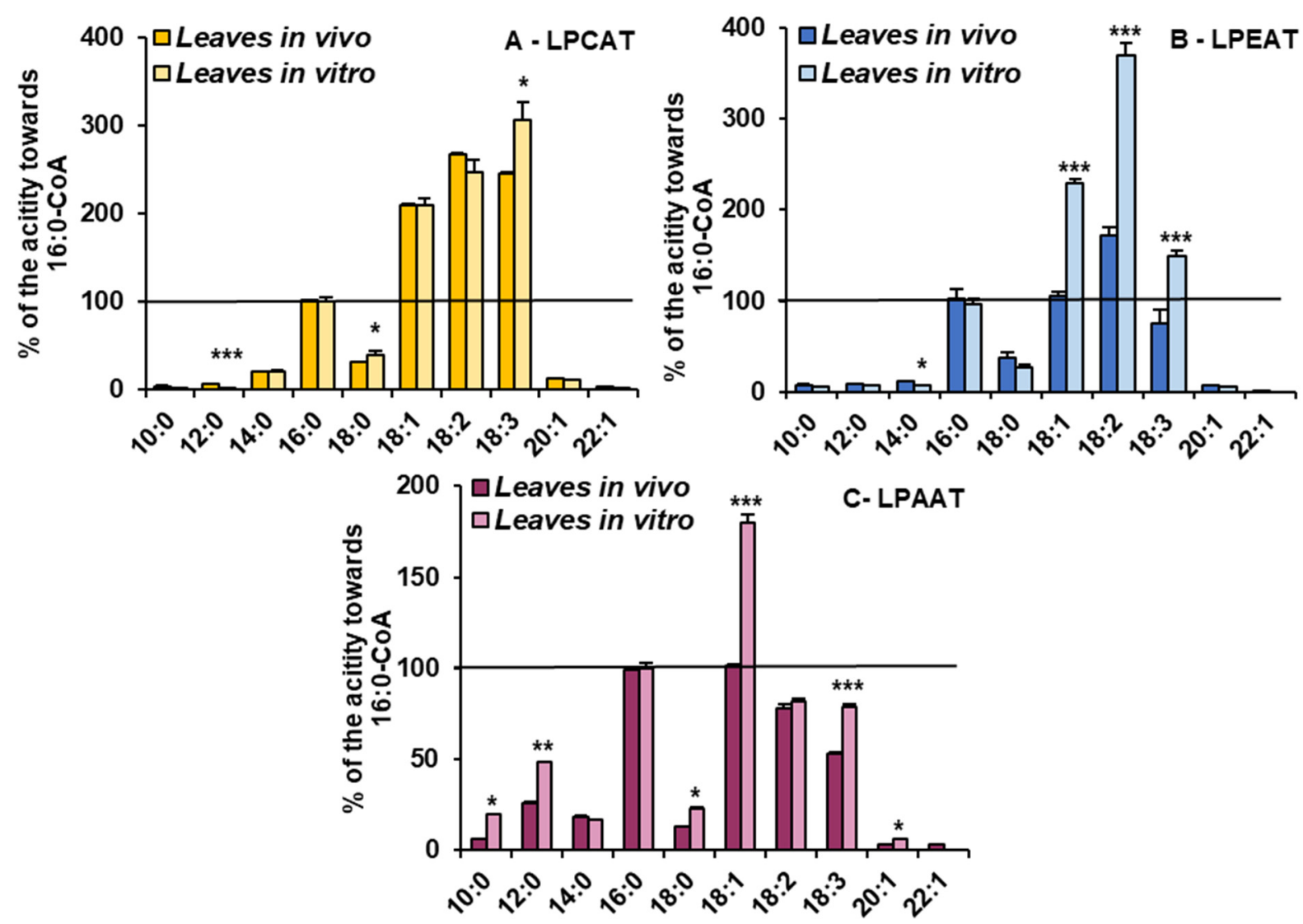

Figure 5. Acyl-CoA (indicated on the figure only by acyl component) preferences of LPCAT (A), LPEAT (B) and LPAAT (C) enzymes present in Camelina sativa leaves cultivated in two different growth conditions: in vivo and in vitro. Mean values and SD are presented (data from at least three independent assays). Asterisks indicate significant difference between the relative activity towards given acyl donor in assays with microsomal fractions of leaves cultivated in vivo and in vitro in a two-tailed Student's $t$-test: ${ }^{*} p \leq 0.05,{ }^{* *} p \leq 0.01,{ }^{* * *} p \leq 0.001$.

\subsection{Phospholipid Remodelling Intensity in C. sativa Leaves from In Vivo and In Vitro Conditions}

Assays evaluating phospholipid remodelling intensity were performed with microsomal fractions from C. sativa leaves from in vivo and in vitro conditions. Each assay contained only $\left[{ }^{14} \mathrm{C}\right]$ acyl-CoA and aliquots of the tested microsomes. Assays were incubated for 5 and $60 \mathrm{~min}$ and the radioactivity in PC, PE and PA of the obtained chloroform extracts was measured. From the amount of de novo synthesised appropriate $\left[{ }^{14} \mathrm{C}\right]$-phospholipids during 60 min incubation, we subtracted those lipids that were synthesised during the 5 min incubation period. We expected that during that time all the endogenous lysophospholipids should have been totally used, as forward reaction performed by LPLAT enzymes is very fast [19]. Thus, the remaining de novo synthesised [ $\left.{ }^{14} \mathrm{C}\right]$-phospholipids were treated as the result of the remodelling process.

The remodelling intensity of PC, PE and PA evaluated in this way was from about 3 to 4 times faster in assays with a microsomal fraction of in vitro leaves than in assays with a microsomal fraction of in vivo leaves (Table 2). The acyl-CoA present in assays also affected the remodelling intensity. The highest remodelling intensity was in assays with $\left[{ }^{14} \mathrm{C}\right] 18: 1-\mathrm{CoA}$ followed by assays with $\left[{ }^{14} \mathrm{C}\right] 18: 2-\mathrm{CoA}$ and $\left[{ }^{14} \mathrm{C}\right] 18: 3-\mathrm{CoA}$. In the case of PA remodelling intensity, the differences between assays with the last two mentioned acyl-CoAs were not as clear. The intensity of remodelling in assays with 18:1-CoA was about 1.7-2.8 times higher than in assays with the two other acyl-CoAs. 
Table 2. Remodelling intensity- $\left[{ }^{14} \mathrm{C}\right]$ acyl group incorporation from $\left[{ }^{14} \mathrm{C}\right]$ acyl-CoA into PC, PE and PA of microsomal fractions of Camelina sativa leaves cultivated in in vivo and in vitro growth conditions. Asterisks indicate significant difference between remodelling intensity (in assays with each tested acyl donor) of indicated phospholipids of microsomal fractions from leaves cultivated in vivo and in vitro in a two-tailed Student's $t$-test, ${ }^{* *} p \leq 0.01,{ }^{* * *} p \leq 0.001$.

\begin{tabular}{|c|c|c|c|c|}
\hline \multirow[t]{2}{*}{$\begin{array}{l}\text { Type of } \\
\text { Cultivation } \\
\text { Condition }\end{array}$} & \multirow[t]{2}{*}{$\begin{array}{c}\text { Fatty Acid } \\
\text { Donors }\end{array}$} & \multicolumn{3}{|c|}{$\begin{array}{c}\text { Remodelling Intensity } \\
\text { (pmol }\left[{ }^{14} \mathrm{C}\right] \mathrm{PL} / \mathrm{nmol} \text { Microsomal PC/min) }\end{array}$} \\
\hline & & PC & PE & PA \\
\hline \multirow{4}{*}{ In vitro } & {$\left[{ }^{14} \mathrm{C}\right] 18: 1-\mathrm{CoA}$} & $\begin{array}{c}3.18^{* * *} \\
+0.07\end{array}$ & $\begin{array}{c}0.59 * * * \\
+0.01\end{array}$ & $\begin{array}{l}0.26^{* * * *} \\
+0.02\end{array}$ \\
\hline & {$\left[{ }^{14} \mathrm{C}\right] 18: 2-\mathrm{CoA}$} & $\begin{array}{c}1.56^{* * *} \\
+0.05\end{array}$ & $\begin{array}{c}0.31 * * * \\
+0.02\end{array}$ & $\begin{array}{l}0.1^{* *} \\
+0.008\end{array}$ \\
\hline & \multirow{2}{*}{${ }^{14} \mathrm{C} 18: 3-\mathrm{CoA}$} & $1.3^{* * *}$ & $0.21 * * *$ & $0.12 * * *$ \\
\hline & & \pm 0.09 & \pm 0.007 & \pm 0.009 \\
\hline \multirow{5}{*}{ In vivo } & {$\left[{ }^{14} \mathrm{C}\right] 18: 1-\mathrm{CoA}$} & 0.85 & 0.15 & 0.03 \\
\hline & \multirow{2}{*}[{}^{14}\mathrm{C}]{$18: 2-\mathrm{CoA}$} & $\begin{array}{c} \pm 0.01 \\
0.47\end{array}$ & $\begin{array}{c} \pm 0.01 \\
0.09\end{array}$ & $\begin{array}{c} \pm 0.002 \\
0.03\end{array}$ \\
\hline & & \pm 0.01 & \pm 0.005 & \pm 0.001 \\
\hline & \multirow{2}{*}{${ }^{14} \mathrm{C} 18: 3-\mathrm{CoA}$} & 0.43 & 0.07 & 0.06 \\
\hline & & \pm 0.02 & \pm 0.005 & \pm 0.001 \\
\hline
\end{tabular}

Assuming that the proportions between PC, PE and PA in microsomal fractions were similar to those in leaves used for their preparation (see Figure 3), the complete turnover of fatty acids (in assays with 18:1-CoA) of PC should take about $10 \mathrm{~h}$ in in vitro conditions and about $39 \mathrm{~h}$ in in vivo conditions. In the case of PE, it would be about $17 \mathrm{~h}$ and $95 \mathrm{~h}$, respectively, and in the case of PA about $2 \mathrm{~h}$ and $6 \mathrm{hrs}$. As the deacylation (part of the acyl edition process) of phospholipids undergoing remodelling is faster in the $s n-2$ position than at the $s n-1$ position, the time of turnover of fatty acids at the $s n-2$ position should be shorter and at the $s n-1$ position should be longer than presented above (calculated for all fatty acids present in both $s n-1$ and $s n-2$ positions) [23].

\section{Discussion}

In vitro methods of plant cultivation are currently widely used both in agricultural practice and in scientific research. The results obtained from plants from in vitro conditions are often extrapolated to in vivo conditions. However, the environment of plants growing in vitro is completely different from that in vivo. Thus, the metabolic processes occurring in vitro can also deviate from those from in vivo conditions. Despite this, research concerning such effects is rather rare, especially in the area of plant lipid biochemistry. To bridge this gap in knowledge, in the presented studies we investigated the effects of in vitro conditions on lipid contents and composition, on the activity and substrate specificity of LPLAT enzymes (the most important enzymes in the acyl editing process of phospholipids) as well as on the intensity of the phospholipid remodelling of C. sativa leaves.

\subsection{In Vitro Growth Conditions Clearly Decline Prokaryotic Pathway Activity}

So far, most of the research concerning acyl-lipid contents and composition has been conducted on A. thaliana. Data on C. sativa are still missing. Our results concerning the fatty acid composition of acyl-lipids in C. sativa leaves show that this plant possesses a similar composition of fatty acids to A. thaliana, both when plants are cultured in in vivo $[16,34,35]$ and in in vitro conditions [31]. The composition of individual lipid classes in leaves from in vivo conditions also seems to be comparable to that of $A$. thaliana [16]. However, none of these studies concerns comparative analysis between the two types of plant cultivation conditions. 
Significant differences have been noticed for the fatty acid composition of individual lipid classes, especially for PE and PC, which were characterised by the dominance of linolenic acid (18:3) over linoleic acid (18:2) in C. sativa, whereas for $A$. thaliana the opposite was observed [34]. In the case of galactolipids, MGDG exhibited similar patterns, while DGDG composition was completely different to that of $A$. thaliana. In DGDG of Arabidopsis leaves, 16:0 significantly dominated over other fatty acids, and in DGDG of $C$. sativa leaves the level of palmitic acid was only a bit higher than the level of $18 \mathrm{C}$ unsaturated fatty acids [34]. Hitherto, for in vitro conditions such experiments have not been conducted.

One of the most visible discrepancies in the fatty acid composition of acyl-lipids of $C$. sativa leaves from in vivo and in vitro conditions is the amount of trienoic fatty acids. Their relative amount was reduced from about $72 \%$ in in vivo conditions to about $52 \%$ in in vitro conditions. With regard to individual lipid classes, a reduction in the relative amount of 18:3 was visible mostly in PC and to some extent in both galactolipids. The reduction in the relative amount of 16:3 primarily concerned the MGDG pool.

Trienoic fatty acids play an essential role in plant adaptation to unfavourable environmental conditions, especially to temperature changes. Their amount rises in cold temperatures and decreases in high temperatures. In addition to boosting tolerance to temperature, these fatty acids are also a source of carbon when they are stored in the TAG pool, are precursors of bioactive molecules and are necessary in stress signalisation [36-39].

A reduction in trienoic fatty acids has a key effect on membrane fluidity by leading to membrane rigidisation and changes in its conformation. Higashi et al. [40] observed that during stress conditions (heat stress), 18:3 is efficiently removed from the MGDG pool with a simultaneous increase in its level in storage lipids. Similarly to this result, in C. sativa leaves cultivated in in vitro conditions, we observed an elevated level of neutral lipids with contents of 18:3 increased up to 10\% (Supplemental Table S1). Thus, in vitro conditions caused a similar effect to the abovementioned heat stress conditions. In vitro conditions also caused a significant decline in the galactolipid levels and an increase in phospholipid levels, especially PC and PE. However, as the total acyl-lipid level was about 2.5 times higher in in vivo conditions, the absolute amount of PC and PE calculated per unit of dry weight still remained a bit lower than in in vivo plants. Thus, in vitro conditions visibly decreased prokaryotic pathway activity. The physiological role of this rearrangement in acyl-lipid biosynthetic pathways needs to be elucidated in further studies.

\subsection{LPLAT Enzyme Activity and Remodelling Intensity Are Enhanced in In Vitro Cultivated Leaves}

In the presented studies, we investigated the effect of in vitro conditions not only on LPCAT, LPEAT and LPAAT activity, but also on their specificity towards acyl-CoAs. The overall activity of the tested LPLATs was at least 2 times higher in in vitro conditions compared to in vivo. This could be caused by (i) an increased expression of appropriate genes (causing an increased synthesis of the tested acyltransferases), or (ii) by enhancing posttranslational activity, leading to the increased synthesis of the tested LPLATs, or (iii) by the lower catabolism of these enzymes. According to Klińska et al. [23], the expression level of LPEAT-encoding genes in C. sativa leaves from in vivo conditions was higher than in their in vitro counterparts. Thus, at least in the case of LPEAT enzymes, their higher activity in in vitro leaves seems not to be connected with the elevated expression levels of their encoding genes. The physiological significance of enhancing the activity of LPLAT enzymes in in vitro conditions might be connected with the observed increased intensity (at least 3 times) of the remodelling of PC, PE and PA. The LPLAT type of enzymes could be involved not only in the synthesis of appropriate phospholipids from lysophospholipids created during the first step of the remodelling process, but also in the creation of the lysophospholipid pool via backward reactions performed by these enzymes $[19,20,22]$. However, the relative share of the LPLAT type of enzymes in the deacylation process of the mentioned phospholipids needs to be elucidated in further studies as well as the significance of the elevated remodelling intensity of phospholipids for plant development in in vitro conditions. 
The specificity of LPCATs of $C$. sativa leaves towards acyl-CoA does not differ much from LPCATs from other plants $[19,21,41]$. All of them were highly specific toward 18C unsaturated fatty acids. In vitro conditions also caused only small changes to their preferences to acyl-CoAs. Some differences were noted mostly towards 18:2-CoA and 18:3-CoA. The former favoured acyl-CoA in in vivo and the latter in in vitro growth conditions.

So far, only the substrate specificity of LPEAT enzymes from A. thaliana and C. sativa was tested $[22,23,42,43]$. These studies revealed high preferences of these enzymes towards 16:0-CoA as well as towards unsaturated 18C-acyl-CoAs. We also observed similar preferences in our studies. However, we also noticed that in vitro conditions significantly enhanced the affinity of LPEATs towards 18C-unsaturated acyl-CoA compared with the activity towards 16:0-CoA. This could be explained by an enhancement of the expression levels of specific isoforms of LPEATs or by changes in the lipid composition of membranes surrounding the LPEATs. In C. sativa, there are six different isoforms of LPEATs and their expression patterns vary in different organs [23]. It has also been shown that isoforms of LPEATs of $C$. sativa present in microsomal fractions of transgenic yeast (harbouring genes encoding these isoforms) expressed affinity towards other acyl-CoAs than LPEATs present in microsomal membranes prepared from C. sativa plants [23]. Thus, from the obtained results, we cannot conclude which of these factors is responsible for the observed changes in LPEAT specificity towards acyl-CoA in in vitro conditions.

The substrate specificity of LPAAT enzymes was tested in many plant species, such as Brassica napus, Camelina sativa, Limananthes alba, Linum usitatissimum, Ricinus communis, Syagrus cocoides Martius and Zea mays [22,44-47]. All of the mentioned studies revealed the diverse substrate specificity of these enzymes, ranging from preference towards short fatty acids to preference towards very-long-chain fatty acids such as 22:1. In our studies, the tested LPAATs of $C$. sativa leaves accepted a wide variety of acyl-CoAs, with the highest preference equally towards 16:0-CoA and 18:1-CoA in in vivo conditions. This substrate specificity was to some extent modified by in vitro conditions. Generally, most of the acyl-CoAs were better utilised when comparing their activity with the activity towards 16:0-CoA. This could be (similarly to the LPEAT enzymes discussed above) caused by different expressions of specific isoforms of LPAATs in in vitro conditions as well as by different environments of LPAAT enzymes. In C. sativa, 15 different isoforms encoding LPAATs are present, also exhibiting different expression patterns [48,49]. We have also shown that the membrane lipid compositions of $C$. sativa leaves from in vivo and in vitro conditions are quite different, which might be an effect of the observed discrepancies.

An interesting finding of our studies is the effect of acyl-CoA on lipid remodelling intensity. The addition of 18:1-CoA to the reaction mixture caused higher acyl editing intensity compared with the addition of 18:2-CoA and especially 18:3-CoA. Similar observations were noticed previously in assays with microsomal fractions of $C$. sativa seeds $[21,22]$ and leaves [23]. Thus, this seems to be a commonplace phenomenon. However, the question remains open concerning the nature of this phenomenon. Are LPLAT enzymes characterised by different deacylation activities after binding different acyl-CoAs? Or are there other deacylation enzymes such as phospholipases or enzymes of the PDAT type that are more active? These questions require further and more detailed studies.

\section{Conclusions}

The presented results clearly indicate that growth conditions significantly influence acyl-lipid metabolism. The discrepancies between in vivo and in vitro conditions occur in total acyl-lipid contents, in the composition of acyl-lipid classes, in LPLAT enzyme activity and substrate specificity and in phospholipid remodelling intensity. Consequently, the results from experiments conducted on in vitro cultivated plants should only be applied to the standard conditions with caution, especially when lipid metabolism is concerned.

Supplementary Materials: The following are available online at https: / www.mdpi.com/article / 10.3390/cells10092326/s1, Table S1: Relative amount of different fatty acids in neutral lipid classes present in C. sativa leaves cultured in in vivo and in vitro conditions. 
Author Contributions: Conceptualization, S.K. (Sylwia Klińska) and A.B.; methodology, S.K. (Sylwia Klińska) and A.B.; investigation, S.K. (Sylwia Klińska), S.K. (Sara Kędzierska) and K.J.-G.; data curation, S.K. (Sylwia Klińska); writing—original draft preparation, S.K. (Sylwia Klińska) and A.B.; writing-review and editing, S.K. (Sylwia Klińska) and A.B.; supervision, S.K. (Sylwia Klińska) and A.B.; funding acquisition, A.B. All authors have read and agreed to the published version of the manuscript.

Funding: This research was funded by the National Science Centre, Poland; project OPUS 13. Project number: 2017/25/B/NZ3/00721.

Institutional Review Board Statement: Not applicable.

Informed Consent Statement: Not applicable.

Data Availability Statement: The data presented in this study are available on request from the corresponding author. The data are not publicly available due to privacy.

Conflicts of Interest: The authors declare no conflict of interest.

\section{References}

1. Block, M.A.; Dorne, A.J.; Joyard, J.; Douce, R. Preparation and characterization of membrane fractions enriched in outer and inner envelope membranes from spinach chloroplasts. II. Biochemical characterization. J. Biol. Chem. 1983, 258, 13281-13286. [CrossRef]

2. Mizusawa, N.; Wada, H. The role of lipids in photosystem II. Biochim. Biophys. Acta Bioenerg. 2012, 1817, 194-208. [CrossRef]

3. Dörmann, P. Galactolipids in Plant Membranes. In Enclopedia of Life Sciences; Jon Wiley \& Sons Ltd.: Hobokern, NJ, USA, 2013.

4. Kobayashi, K.; Endo, K.; Wada, H. Roles of lipids in photosynthesis. In Lipids in Plant and Algae Development; Nakamura, Y., Li-Beisson, Y., Eds.; Springer International Publishing: Cham, Switzerland, 2016; pp. 21-49.

5. Ohlrogge, J.; Browse, J. Lipid biosynthesis. Plant Cell 1995, 7, 957-970.

6. Birner, R.; Bürgermeister, M.; Schneiter, R.; Daum, G. Roles of phosphatidylethanolamine and of its several biosynthetic pathways in Saccharomyces cerevisiae. Mol. Biol. Cell 2001, 12, 997-1007. [CrossRef]

7. Gibellini, F.; Smith, T.K. The Kennedy pathway-De novo synthesis of phosphatidylethanolamine and phosphatidylcholine. IUBMB Life 2010, 62, 414-428. [CrossRef]

8. Jasieniecka-Gazarkiewicz, K.; Demski, K.; Gidda, S.K.; Klińska, S.; Niedojadło, J.; Lager, I.; Carlsson, A.S.; Minina, E.A.; Mullen, R.T.; Bozhkov, P.V.; et al. Subcellular Localization of Acyl-CoA: Lysophosphatidylethanolamine Acyltransferases (LPEATs) and the Effects of Knocking-Out and Overexpression of Their Genes on Autophagy Markers Level and Life Span of A. thaliana. Int. J. Mol. Sci. 2021, 22, 3006. [CrossRef]

9. Testerink, C.; Munnik, T. Molecular, cellular, and physiological responses to phosphatidic acid formation in plants. J. Exp. Bot. 2011, 62, 2349-2361. [CrossRef]

10. Meijer, H.J.; Munnik, T. Phospholipid-based signaling in plants. Annu. Rev. Plant Biol. 2003, 54, 265-306. [CrossRef]

11. Dörmann, P. Membrane lipids. In Plant Lipids. Biology, Utilisation and Manipulation; Murphy, D.J., Ed.; Blackwell Publishing Ltd.: Oxford, UK, 2005; pp. 123-161.

12. Kennedy, E.P. Biosynthesis of complex lipids. Fed. Proc. 1961, 20, 934-940.

13. Frentzen, M. Acyltransferases from basic science to modified seed oils. Fett/Lipid 1998, 100, 161-166. [CrossRef]

14. Slack, C.R.; Campbell, L.C.; Browse, J.A.; Roughan, P.G. Some evidence for the reversibility of the cholinephosphtranferasecatalysed reaction in developing linseed cotyledons in vivo. Biochem Biophys. Acta 1983, 754, 10-20. [CrossRef]

15. Somerville, C.; Browse, J.; Jaworski, J.G.; Ohlorgge, J.B. Lipids. In Biochemistry and Molecular Biology of Plants; Buchnanan, B.B., Gruissem, W., Jones, J.L., Eds.; American Society of Plant Biologists: Rockville, MD, USA, 2001; pp. $456-527$.

16. Li-Beisson, Y.; Shorrosh, B.; Beisson, F.; Andersson, M.X.; Arondel, V.; Bates, P.D.; Baud, S.; Bird, D.; Debono, A.; Durrett, T.P.; et al. Arabidopsis Book; Robt, L., Ed.; American Society of Plant Biologist: Rockville, MD, USA, 2013; pp. 1-70.

17. Joyard, J.; Block, M.A.; Malherbe, A.; Marachal, E.; Douce, R. Origin and synthesis of galactolipid and sulfolipid headgroups. In Lipid Metabolism in Plants; Moore, T.S., Ed.; CRC Press: Boca Raton, FA, USA, 1993; pp. 231-258.

18. Lands, W.E. Metabolism of glycerolipides; a comparison of lecithin and triglyceride synthesis. J. Biol. Chem. 1958, 231, 883-888. [CrossRef]

19. Lager, I.; Yilmaz, J.L.; Zhou, X.R.; Jasieniecka, K.; Kazachkov, M.; Wang, P.; Zou, J.; Weselake, R.; Smith, M.A.; Bayon, S.; et al. Plant acyl-CoA:lysophosphatidylcholine acyltransferases (LPCATs) have different specificities in their forward and reverse reactions. J. Biol. Chem. 2013, 288, 36902-36914. [CrossRef]

20. Jasieniecka-Gazarkiewicz, K.; Demski, K.; Lager, I.; Stymne, S.; Banaś, A. Possible role of different yeast and plant lysophospholipid:acyl-CoA acyltransferases (LPLATs) in acyl remodelling of phospholipids. Lipids 2016, 51, 15-23. [CrossRef]

21. Klińska, S.; Jasieniecka-Gazarkiewicz, K.; Banaś, A. Acyl-CoA: AzdLysophosphatidylcholine acyltransferases (LPCATs) of Camelina sativa seeds: Biochemical properties and function. Planta 2019, 250, 1655-1670. [CrossRef]

22. Klińska, S.; Jasieniecka-Gazarkiewicz, K.; Demski, K.; Banaś, A. Editing of phosphatidic acid and phosphatidylethanolamine by acyl-CoA: Lysophospholipid acyltransferases in developing Camelina sativa seeds. Planta 2020, 10, 4. [CrossRef] 
23. Klińska, S.; Demski, K.; Jasieniecka-Gazarkiewicz, K.; Banaś, A. LPEATs Tailor Plant Phospholipid Composition through Adjusting Substrate Preferences to Temperature. Int. J. Mol. Sci. 2021, 22, 8137. [CrossRef]

24. Cardoso, J.C.; de Oliveira, B.E.B.S.; Cardoso, F.d.I. Advances and challenges on the in vitro production of secondary metabolites from medicinal plants. Hortic. Bras. 2019, 37, 124-132. [CrossRef]

25. Verpoorte, R.; Contin, A.; Memelink, J. Biotechnology for the production of plant secondary metabolites. Phytochem. Rev. 2002, 1, 13-25. [CrossRef]

26. Grzegorczyk-Karolak, I.; Matkowski, A.; Wysokińska, H. Antioxidant activity of extracts from in vitro cultures of Salvia officinalis L. Food Chem. 2007, 104, 536-541. [CrossRef]

27. Khorasani, A.; Winardi, S.; Koshy, P.; Rosna, T.; Arash, R. Antioxidant and antibacterial activities of ethanolic extracts of Asparagus officinalis cv. Mary Washington: Comparison of in vivo and in vitro grown plant bioactivities. Afr. J. Biotechnol. 2010, 9, 8460-8466.

28. Park, W.; Feng, Y.; Ahn, S.J. Alteration of leaf shape, improved metaltolerance, and productivity of seed by overexpression of CsHMA3 in Camelina sativa. Biotechnol. Biofuels. 2014, 7, 96. [CrossRef]

29. Yuan, L.; Mao, X.; Zhao, K.; Ji, X.; Ji, C.; Xue, J.; Li, R. Characterisation of phospholipid: Diacylglycerol acyltransferases (PDATs) from Camelina sativa and their roles in stress responses. Biol. Open 2017, 6, 1024-1034. [CrossRef]

30. Yuan, L.; Mao, X.; Zhao, K.; Sun, Y.; Ji, C.; Xue, J.; Li, R. Spatio-temporal expression and stress responses of DGAT1, DGAT2 and PDAT responsible for TAG biosynthesis in Camelina sativa. Emir. J. Food Agric. 2017, 29, 274-284. [CrossRef]

31. Demski, K.; Łosiewska, A.; Jasieniecka-Gazarkiewicz, K.; Klińska, S.; Banaś, A. Phospholipid:diacylglycerol acyltransferase1 overexpression delays senescence and enhances post-heat and cold exposure fitness. Front. Plant Sci. 2020, 11, 611897. [CrossRef]

32. Bligh, E.G.; Dyer, W.J. A rapid method of total lipid extraction and purification. Can. J. Biochem. 1959, 37, 911-917.

33. Sánchez, M.; David, G.N.; David, N.B. The relationship between palmitoyl-coenzyme A synthetase activity and esterifcation of sn-glycerol 3-phosphate in rat liver mitochondria. Biochem. J. 1973, 132, 697-706. [CrossRef]

34. Miquel, M.; Browse, J. Arabidopsis mutants deficient in polyunsaturated fatty acid synthesis. Biochemical and genetic characterization of a plant oleoyl-phosphatidylcholine desaturase. J. Biol. Chem. 1992, 267, 1502-1509. [CrossRef]

35. Falcone, D.L.; Ogas, J.P.; Somerville, C.R. Regulation of membrane fatty acid composition by temperature in mutants of Arabidopsis with alterations in membrane lipid composition. BMC Plant Biol. 2004, 4, 17. [CrossRef]

36. Murakami, Y.; Tsuyama, M.; Kobayashi, Y.; Kodama, H.; Iba, K. Trienoic Fatty Acids and Plant Tolerance of High Temperature. Science 2000, 287, 476-479. [CrossRef]

37. Yaeno, T.; Matsuda, O.; Iba, K. Role of chloroplast trienoic fatty acids in plant disease defense responses. Plant J. 2004, 40, 931-941. [CrossRef]

38. Wang, K.; Guo, Q.; Froehlich, J.E.; Hersh, H.L.; Zienkiewicz, A.; Howe, G.A.; Benning, C. Two abscisic acid-responsive plastid lipase genes involved in jasmonic acid biosynthesis in Arabidopsis thaliana. Plant Cell. 2018, 30, 1006-1022. [CrossRef] [PubMed]

39. He, M.; Ding, N.-Z. Plant Unsaturated Fatty Acids: Multiple Roles in Stress Response. Front. Plant Sci. 2020, 11, 562785. [CrossRef] [PubMed]

40. Higashi, Y.; Okazaki, Y.; Takano, K.; Myouga, F.; Shinozaki, K.; Knoch, E.; Fukushima, A.; Saito, K. Remodels chloroplastic monogalactosyldiacylglycerol by liberating $\alpha$-linolenic acid in Arabidopsis leaves under heat stress. Plant Cell. 2018, 30, 1887-1905. [CrossRef]

41. Pan, X.; Chen, G.; Kazachkov, M.; Greer, M.S.; Caldo, K.M.; Zou, J.; Weselake, R.J. In vivo and in vitro evidence for biochemical coupling of reactions catalyzed by lysophosphatidylcholine acyltransferase and diacylglycerol acyltransferase. J. Biol. Chem. 2015, 290, 18068-18078. [CrossRef]

42. Stålberg, K.; Ståhl, U.; Stymne, S.; Ohlrogge, J. Characterization of two Arabidopsis thaliana acyltransferases with preference for lysophosphatidylethanolamine. BMC Plant Biol. 2009, 9, 60. [CrossRef]

43. Jasieniecka-Gazarkiewicz, K.; Lager, I.; Carlsson, A.S.; Gutbrod, K.; Peisker, H.; Dörmann, P.; Stymne, S.; Banaś, A. AcylCoA:Lysophosphatidylethanolamine Acyltransferase Activity Regulates Growth of Arabidopsis. Plant Physiol. 2017, 174, 986-998. [CrossRef]

44. Oo, K.C.; Huang, A.H. Lysophosphatidate acyltransferase activities in the microsomes from palm endosperm, maize scutellum, and rapeseed cotyledon of maturing seeds. Plant Physiol. 1989, 91, 1288-1295. [CrossRef]

45. Lassner, M.W.; Levering, C.K.; Davies, H.M.; Knutzon, D.S. Lysophosphatidic acid acyltransferase from meadowfoam mediates insertion of erucic acid at the sn-2 position of triacylglycerol in transgenic rapeseed oil. Plant Physiol. 1995, 109, 1389-1394. [CrossRef]

46. Arroyo-Caro, J.M.; Chileh, T.; Kazachkov, M.; Zou, J.; Alonso, D.L.; García-Maroto, F. The multigene family of lysophosphatidate acyltransferase (LPAT)-related enzymes in Ricinus communis: Cloning and molecular characterization of two LPAT genes that are expressed in castor seeds. Plant Sci. 2013, 199-200, 29-40. [CrossRef]

47. Fahs, Z.; Rossez, Y.; Guénin, S.; Gutierrez, L.; Thomasset, B.; Perrin, Y. Cloning and molecular characterization of three lysophosphatidic acid acyltransferases expressed in fax seeds. Plant Sci. 2019, 280, 41-50. [CrossRef]

48. Abdullah, H.M.; Akbari, P.; Paulose, B.; Schnell, D.; Qi, W.; Park, Y.; Pareek, A.; Dhankher, O.P. Transcriptome profling of Camelina sativa to identify genes involved in triacylglycerol biosynthesis and accumulation in the developing seeds. Biotechnol Biofuels 2016, 9, 136. [CrossRef] [PubMed]

49. Kagale, S.; Koh, C.; Nixon, J.; Bollina, V.; Clarke, W.E.; Tuteja, R.; Spillane, C.; Robinson, S.J.; Links, M.G.; Clarke, C.; et al. The emerging biofuel crop Camelina sativa retains a highly undifferentiated hexaploid genome structure. Nat. Commun. 2014, 5, 3706. [CrossRef] 